\title{
DE LOS ALTARES A LAS ESTANTERÍAS. MAGIA, DIOSES Y RELIGIÓN EN PROMETHEA DE ALAN MOORE ${ }^{1}$
}

\author{
Ruben Gregori \\ Iniversitat de València
}

\begin{abstract}
Resumen: La pervivencia de los dioses y diosas en el imaginario colectivo ha sido una constante a lo largo de toda la historia de las imágenes. Por ello, no resulta extraño que encontremos entre las páginas de los cómics referencias visuales que nos trasladen a los mitos paganos o a las iconografías cristianas. Fruto de la coincidencia o de la más absoluta intencionalidad, los ejemplos son muchos y variados, y de entre todos ellos, por su eclecticismo y su magia, cabría destacar Promethea de Alan Moore.
\end{abstract}

Palabras clave: imagen, Alan Moore, cómic, dioses, mitos, mágia, Promethea.

From the altars to the shelves. Magic, gods and religion in Alan Moore's Promethea

Abstract: The survival of the gods and goddesses on the collective imaginary has been a constant throughout the whole history of images. Therefore, it is not weird that we find in the comic book pages visual references about the pagan myths or about Christian iconography. As a result of the coincidence or to the most absolute intentionality, the examples are many and varied. And from all of them, by its eclecticism and magic, we should highlight Promethea by Alan Moore.

Key words: image, Alan Moore, comic, gods, myths, magic, Promethea.

Desde que el mundo es mundo, dioses y diosas han poblado los sueños y las oraciones de los mortales que, acuciados por la necesidad de dar una explicación a su propia existencia, buscaron o imaginaron seres divinos con los que intentar esclarecer los misterios que envolvían, y que aún envuelven, la creación del universo. De entes abstractos a personificaciones antropomórficas con sentimientos o emociones, dotados de condiciones humanas, pasando por fuerzas de la naturaleza con voluntad propia, cada civilización y/o sociedad ha ido aportando su propia concepción de la divinidad con la certeza de saberse la genuina y auténtica, lo que provocó enfrentamientos bélicos cuyos ecos aún perduran en la actualidad. Con el paso de los siglos, muchas de esas entidades

Data de recepció: 20 de maig de 2019 / Data d'acceptació: 2 d'octubre de 2019.

${ }^{1}$ Quisiéramos agradecer los consejos de Noël Martínez y Conrado Martín y la corrección y ayuda de Amadeo Serra. 
fueron relegadas al olvido, sus mitos perdidos o integrados en leyendas posteriores. Algunos como los Olímpicos, los Æsir o los dioses egipcios tuvieron mayor suerte y su popularidad se mantuvo aún con la instauración de las religiones monoteístas como las portadoras de la auténtica verdad, quizás porque en estos casos las deidades eran un reflejo de la propia humanidad, condenadas a sufrir y experimentar las mismas pasiones que los seres que habían creado.

Si bien las tradiciones orales y escritas mantuvieron y difundieron las fábulas e historias en torno a los dioses precristianos, no menos importante fue la labor de las expresiones artísticas, las cuales ayudaron a preservar y nutrir la imagen que de estas divinidades se tenía. Cabe decir, no obstante, que tras la caída del Imperio Romano de Occidente (476) y el arraigo del cristianismo por toda Europa, las representaciones de estas entidades perdieron su protagonismo, y, sin llegar a desaparecer, fueron camufladas en imágenes de astros, alegorías u horóscopos durante todo el medievo hasta su resurgir como deidades al uso a partir del Renacimiento (Mathews, 1993). En su conferencia realizada en el Congreso Internacional de Historia del Arte el 1912, Aby Warburg daba a conocer distintos y variados ejemplos en los que los moradores del Olimpo habían continuado manifestándose a lo largo de la Edad Media entre los frescos del Palazzo Schifanoia.

\section{LA ETERNIDAD DE LOS DIOSES}

Con ello advertimos que la suerte de estos personajes divinos ha ido variando a lo largo de los siglos de acuerdo a las distintas transformaciones sociales, culturales, históricas o teológicas que han ido modificando el pensamiento de la humanidad. No obstante, su popularidad siempre ha sido tal que, de un modo u otro, se han mantenido en el imaginario colectivo y aún a día de hoy podemos encontrar, incluso con mayor facilidad que en siglos anteriores, representaciones de Thor, Hércules o Osiris. A esto ha ayudado la aparición y difusión de nuevos canales de comunicación visual como el cine, los cómics o los videojuegos. Ejemplos como Clash of the Titans (la dirigida por Desmond David en 1981 y el remake de 2010) o las diversas de Hércules como la de Disney (1997) dan testimonio de la recepción y prevalencia de la mitología en el séptimo arte. Del mismo modo, también han encontrado su espacio en las nuevas esferas visuales los santos y personajes del Antiguo y Nuevo Testamento como demuestran las numerosas cintas en torno a la vida del Redentor y de entre las que destaca The Passion of the Christ (2004) de Mel Gibson por su crudeza y sadismo. 
Asimismo, vemos esta pervivencia de dioses y diosas en el plano de los videojuegos como Age of Mythology (2002) o God of War (2005) y secuelas en los que no solamente encontramos a divinidades olímpicas y nórdicas, sino también seres mitológicos como centauros o arpías (Rough, 2016). Sin embargo, al margen de estos ejemplos, será en los cómics y novelas gráficas ${ }^{2}$ donde encontraremos los mayores ejemplos de la pervivencia de iconografías y personajes vinculados al mundo de la religión, a veces encubiertos y otras de forma directa. Así pues, uno de los mayores y más conocidos ejemplos correspondería a la figura de Thor, dios asgardiano e integrante de los Vengadores. La historia de este personaje es ampliamente conocida y su fama es tal que incluso se han llegado a hacer un total de tres películas dentro del universo cinematográfico de Marvel en las que él es el protagonista.

Otros casos menos conocidos de cómics interesados en los panteones paganos como el nórdico, olímpico, egipcio, maya o hinduista sería la saga de God Is Dead (Jonathan Hickman y Mike Costa, Avatar Press, 2013-2016). El argumento trata sobre lo que le ocurre al mundo tras el asesinato de Dios por el diablo y cómo los dioses de distintas culturas se enzarzan en una lucha apocalíptica por el control del mismo. El propio Jesucristo aparece como un hippie adicto preocupado por su placer sexual y que rehúye sus obligaciones como benefactor y redentor de la creación, si bien finalmente escogerá el sacrificio eterno para la salvación de la humanidad. Aunque la serie traslada las figuras de los distintos seres divinos a las páginas del cómic, la sinopsis se centra más en recrear batallas celestiales y encuentros eróticos que en exponer un verdadero relato donde reproducir la esencia de los antiguos mitos.

Parecida a este sería la miniserie de Supergod (Warren Ellis y Garrie Gastonny, Avatar Press, 2009-2010) en la que, como en God Is Dead, se representa el fin del mundo a causa de la presencia de los dioses en la Tierra. No obstante,

2 Aunque a lo largo del texto nos referiremos en ocasiones tanto a cómic como a novela gráfica, no estaría de más poder apuntar brevemente qué diferencia hay entre ambas acepciones. Generalmente se concibe al primero como historias cortas publicadas periódicamente mientras que el segundo suele ser la obra completa. La primera vez que se utilizó el término de novela gráfica fue por medio de Will Eisner en 1978 con la publicación de su A Contract With God y que presentó con esta nueva terminología buscando llegar a un público de edad más madura. Si bien no es del todo cierto que Eisner fuese el primero en hacerse eco de la distinción entre un concepto y otro, sí lo fue en capitalizarlo y popularizarlo. No obstante, a día de hoy sigue sin haber consenso en el uso de estos términos separadamente, pues la novela gráfica en su mayoría no deja de ser la recopilación y reedición de los distintos números, sagas o arcos que han aparecido como cómics y por ello encontramos detractores y defensores del uso de ambas definiciones. Liddo, 2009, 16-21; Roth, 2010, sp; Romero-Jódar, 2013, 117-135. 
en este caso son las propias naciones las que, basándose en sus propios mitos y leyendas, crean una serie de entes prodigiosos a imagen y semejanza de los antiguos seres divinos. Por ejemplo, la India da vida a Krishna, Irán a Malak Al-Mawt, el Ángel de la Muerte y China al sucesor de Buda Siddharta Gautama, Maitreya. Como en la obra de Hickman y Costa, el argumento del cómic se centra en retratar la destrucción de la humanidad, aunque Ellis y Gastonny van un paso más allá y lo que establecen es el conflicto entre religiones, pues a cada ente divino se le ha dado a conocer su propio dogma o doctrina y lo que intenta es aplicarlo. Con ello, asistimos a una exageración y magnificación de los enfrentamientos y disputas que en nombre de la verdadera fe ha habido a lo largo de la historia del género humano.

Caso distinto merecería la obra de Neil Gaiman de The Sandman (Neil Gaiman, Sam Kieth y Mike Dringenberg, DC Comics y Vértigo, 1988-1996), uno de los mejores ejemplos de eclecticismo mitológico y fantástico. Tomando como protagonista la personificación antropomórfica del mismo sueño, Gaiman no duda en incluir entre sus 75 números variadísimas referencias a diversas deidades, como en el arco Estación de Nieblas. En este, Lucifer Lucero del Alba, cansado de su cargo como señor del Infierno, decide retirarse y entrega las llaves del mismo a Morfeo ${ }^{3}$. Como consecuencia, llegados de sus respectivos panteones, dioses y diosas como Bast y Anubis, Thor, Odín y Loki, Susanoo, entidades del Caos y del Orden, embajadores de Oberón y Titania -en referencia a A Midsummer Night's Dream (1595/96) de William Shakespeare (1564-1616) - o representantes de la Ciudad de Plata, los ángeles Dumas y Remeil, acuden a ofrecer regalos a cambio de la posibilidad de obtener el control de las tierras del inframundo para sus propósitos.

\section{(DES)SACRALIZACIÓN DE LA IMAGEN CRISTIANA}

En contraste a estos ejemplos, hay otros personajes que, sin ser dioses o diosas, encarnan actitudes y valores pertenecientes al mundo divino, siendo un claro caso el de Superman. Los orígenes de este kryptoniano son en esencia los del mismo Moisés, pues sus padres ante la destrucción de su planeta deciden enviarlo a través del océano del Universo dentro de una cápsula, para que pudiese sobrevivir. De hecho, su verdadero nombre, Kal-El, tiene sus raíces en

${ }^{3}$ La historia de Lucifer se continuó con el spin-off del mismo nombre a cargo de Neil Gaiman y Mick Carey (DC Comics y Vértigo, 1989-1993). La popularidad del personaje ha sido tal que incluso se le ha dedicado una serie de televisión (Lucifer, Tom Kapinos, 2016-presente). 
el alfabeto hebreo, pues $\mathrm{kal}$ significa recipiente. Con el tiempo, el rebautizado Clark Kent se convertirá en guía y protector de la humanidad, en su salvador, autoconsumiéndose pero sin llegar a extinguirse, convertido en leyenda, en símbolo de vida y esperanza y en una suerte de redentor (Moix, 2007, 321326; Unceta Gómez, 2007, 335-336; Lewis, 2010, sp.) cuyo eco en oriente se dará en la posterior figura de Son Goku .

Por otro lado, también disponemos de ejemplos en los que vemos adaptada la iconografía de algunas de las figuras y representaciones más populares del cristianismo. Una muestra de ello la encontraríamos en A Death on the Family (Jim Starlin y Jim Aparo, DC Comics, 1988-1989) donde un Batman arrodillado y con el semblante oculto en la penumbra sostiene entre sus brazos el cuerpo de Robin muerto y del que podemos extraer que tomaría como referencia la imagen de la Pieta $\grave{a}^{5}$. Otros se inspirarían en la crucifixión o en Cristo para plasmar ciertos sucesos llenos de dramatismo como en Marvel 1602 (Neil Gaiman y Andy Kubert, Marvel Comics, 2003). En esta miniserie los héroes del universo Marvel se encuentran viviendo en el siglo XVII debido a unas alteraciones en el espacio-tiempo y Magneto es llevado a una pira para ser ajusticiado por la Inquisición junto a sus hijos Wanda y Pietro. Sin embargo, gracias a los poderes sobre el metal de Erik Lehnsherr, los tres son liberados y la escena representa a Magneto con los brazos extendidos y atado de pies a modo de un crucificado, mientras que a los lados sus hijos se liberan de sus cadenas en unas poses similares a las contorsiones de los ladrones que acompañaron en su martirio al Hijo de Dios.

Sin embargo, posiblemente sea con Chosen (Dark Horse, 2004) de Mark Millar y Peter Gross donde encontremos una de las mayores referencias a la adaptación de sucesos e iconografías pertenecientes al mundo cristiano. Publicado en tres volúmenes, fueron compilados en un único tomo titulado American Jesus: Chosen con el subtítulo Book I, aludiendo a una futura continuación que hasta el momento no se ha dado. La historia trata sobre la supuesta reencarnación de Cristo en un hombre de 33 años llamado Jodie Christianson que cuenta como descubrió que no era un humano corriente cuando a los 12 años

${ }^{4}$ Aunque sin ser una copia de Superman, la historia del protagonista de Dragon Ball emula a la del mismo Moisés y Cristo, pues se le lanza en una cabina espacial a la Tierra para huir de la destrucción del planeta Saiyan y con el tiempo se convertirá no solo en el defensor del mundo, sino también del universo.

${ }^{5}$ El del cruzado de la capa no es el único ejemplo, pues también tenemos los casos de Superman con Supergirl (Crisis on Infinite, Marv Wolfman y George Pérez, DC Comics, 1985-1986) o la de Cíclope y Fénix (Uncanny X-Men The Dark Phoenix Saga, Chris Claremont y John Byrne, Marvel Comics, 1980). 
sobrevivió a un accidente de tráfico mortal. A lo largo de todo el cómic Millar y Gross van presentando distintos pasajes de la vida de Cristo en clave adolescente haciendo referencia a Star Wars o a los X-Men ${ }^{6}$. Así, podemos encontrar el tema de la resurrección de Lázaro adaptado a la del perro Angel, la disputa entre los doctores en un debate con los profesores en el colegio, a su amiga Maggie Kane como María Magdalena y la duda de santo Tomás mediante el párroco Tom O'Higgins que ha perdido la fe. Y, no obstante, descubrimos al final del tercer volumen que, en realidad, Jodie no es la rencarnación de Jesús, sino el hijo del otro, de Satán, revelación que le es dada por una mujer que le acompaña a conocerlo y cuyo nombre es Lilly, referencia a Lilith, madre de los lilims (Round, 2010, 188-202) ${ }^{7}$.

\section{LA DIVINIDAD ILUSTRADA}

Tras este despliegue de ejemplos podemos constatar que la presencia de lo divino en los cómics tiene un papel destacado que, no obstante, no ha podido ser expresado aquí en su totalidad, dado que los referentes mitológicos e iconográficos son ampliamente notorios en numerosos cómics y novelas gráficas como las ediciones de la Biblia ilustrada, siendo un ejemplo Genesis de Robert Crumb (W. W. Norton \& Company, 2009) ${ }^{8}$. Ello demuestra la clara voluntad del ser humano por mantener en el imaginario colectivo las referencias a aquellos entes y dioses en los que se ven reflejados y que han ido plasmando en di-

6 "The teenage motivation extends to the widest level of the text, whose events are redefined in contemporary terms: 'Okay, you got to think of the Old Testament as Star Wars,' continuing, 'Everybody likes it, the characters were great, and its huge success was always gonna change the world forever.' Jodie draws similar parallels between the New Testament and The Empire Strikes Back and between his own life and Return of the Jedi, again with reference to their popularity and fandom". Round, 2010, 189.

7 Este descubrimiento se va dando a conocer en distintos detalles que aparecen a lo largo de las páginas, como las referencias a Darth Vader, padre de Luke Skywalker o por la sombra con cuernos que aparece detrás de la cabeza de Jodie cuando aún está en el hospital y conoce por primera vez a Lilly. Round, 2010, 193.

8 Véanse más ejemplos en Strömberg, 2010, 110-131; Tripp, 2010, sp. Lejos de nuestro campo quedaría el estudio de la presencia de lo divino en el manga y anime y de la que también se detecta en sagas como Dragon Ball (Akira Toriyama, Shūeisha, 1986-actualidad), Saint Seiya (Masami Kurumada, Shūeisha, 1986-1991), Fushigi Yūgi (Yū Watase, Shōgakukan, 1992-1996), Fullmetal Alchemist (Hiromu Arakawa, Square Enix, 20012010), Noragami (Adachitoka, Kōdansha, 2010-actualidad), Nanatsu no Taizai (Nakaba Suzuki, Kōdansha, 2012-actualidad), o los ya clásicos Mononoke Hime (Hayao Miyazaki, 1997) y Sen to Chihiro no kamikakushi (Hayao Miyazaki, 2001). 
versos y numerosos soportes a lo largo de la historia. No hay que olvidar el poder que tienen las imágenes a la hora de definir o describir la realidad o la imaginación, mucho más potente, justamente por su carga visual, que la propia literalidad. De este modo, al representar a la divinidad en el cómic, esta puede reflejarse en un héroe o en un monstruo, en un hombre o en una mujer, en un ángel o en un demonio, o en el bien y en el mal, en el caos y en el orden y en la misma dualidad; pero también en el concepto del tiempo y en el del ser, en una necesidad humana, mística o espiritual y, por supuesto en un anhelo, en un sueño o en una idea. Así, en palabras de Andrew Tripp, "God is all of these images and beyond all of these images, living in our minds and our imaginations as something that cannot be fully named or described except through metaphor and analogy, since no single image adequately defines God." (Tripp, 2010, sp.)

Y ha sido precisamente por medio de estos canales que la humanidad ha encontrado otra forma de trasladar desde los cielos y los infiernos las efigies de dioses y diosas al plano artístico para darles de nuevo voz y presencia entre los mortales. De esta forma, encontrarnos a Thor, Hércules o el mismo Jesucristo entre las páginas de los cómics no nos resulta extraño, pues nuestra cultura visual ha estado constantemente bombardeada por estas figuras e iconografías desde los albores de la humanidad y ahora, bien que, perdida la sacralidad, siguen siendo referentes de los placeres, los anhelos y los deseos de aquellos que los crearon, los imaginaron o los descubrieron. Esta desacralización es asimismo sinónimo de muerte, pues cuando los dioses dejan de ser adorados tienen que ser reinventados (Unceta Gómez, 2007, 333-344; Unceta Gómez, 2013, 825-826) 9 .

No obstante, hay que tener en cuenta que esta metamorfosis de las imágenes a veces es producida desde el mismo inconsciente, afectados como estamos por la exposición masiva de representaciones e ilustraciones. Por tanto, a la hora de analizar la huella de lo divino a partir de iconografías paganas o cristianas, podemos llegar a caer en el error de la sobreinterpretación, más cuando parecemos olvidar que el público al que van dirigido estas historias no tiene que ser uno académico precisamente. Así, algunas de las imágenes que a priori podrían tener un simbolismo o intencionalidad destacada para aquellos versados en el estudio de las mismas, podrían ser meros instrumentos visuales sin carga alguna, producto de la tradición cultural convencionalizada y desaparecida el áurea que les caracterizaba o designaba.

Por ello, dentro de esta vorágine iconográfica, Promethea (1999-2005) de Alan Moore se convierte en uno de los mayores exponentes de la asimilación

9 Asimismo son también interesantes para ampliar estas cuestiones Kovacs y Marshall, 2011 y Kovacs y Marshall, 2016. 
y transformación de imágenes religiosas, tanto por su potente eclecticismo, como por el tratamiento que se le da a causa de la vasta cultura del autor. Publicada dentro de las series de America's Best Comics (1999-2005) en 32 números, Promethea es además obra del dibujante J. H. Williams III y del entintador Mick Gray, los cuales, guiados por las notas de Moore, le confieren una atmósfera más mística y extática con la explosión de formas y colores (Liddo, 2009, 61-62, 85-86). Por otro lado, aparte de la carga teológica y mitológica que contiene, la obra de Moore es también un referente feminista, de la identidad queer y de género por la destacada importancia que reciben estas cuestiones a lo largo de toda la historia. Sin embargo, antes de centrarnos en el contenido del cómic, sería necesario apuntar algunas líneas generales sobre el imaginario de Moore para poder constatar la gran maquinaria intelectual que se esconde detrás de las ideas articuladas en Promethea.

\section{LA MAGIA DE MOORE}

Alan Moore es quizás uno de los escritores y guionistas de cómic más conocidos, importantes e influyentes de las últimas décadas. Algunos de sus trabajos más conocidos serían Swamp Thing (DC Comics, 1984-1987), Watchmen (DC Comics, 1986-1987), Batman: The Killing Joke (DC Comics, 1988), Vfor Vendetta (DC Comics, 1988-1989), From Hell (Top Shelf Productions/Knockabout Comics, 1989-1998) y The League of Extraordinary Gentlemen (ABC/WildStorm/DC Comics, 1999-2007), habiendo sido adaptados a la gran pantalla varios de ellos. Su fascinación por el poder de la palabra como principal vehículo primario para la creación de cómics y novela gráfica provocó que se decidiera a centrarse única y exclusivamente en la planificación y redacción de sus propias obras y abandonar el dibujo.

De esta manera, Moore se yergue como uno de los artífices de cómic más vinculados a la prosa y al relato, por lo que según Liddo "the expression 'graphic novel' is appropriate because it conveys the balance between the weight of the literary tradition and the equally important visual aspect of his works", aunque más adelante recuerda que no todas sus obras entrarían dentro de esta categoría. Su trabajo, realizado en su mayoría desde su residencia en Northampton, Inglaterra, consiste en elaborar un detallado guion hiperdescriptivo con indicaciones y directrices precisas que luego enviará a los dibujantes y entintadores. Sus instrucciones no solamente provienen a los artistas de sugerencias, sino también de entradas históricas, comentarios, colores que deberían aparecer y apuntes sobre sonidos y olores que se pueden encontrar en las distintas páginas (Liddo, 2009, 22, 30, 32). 
Como escritor, Moore siempre ha manifestado su interés por las sagas nórdicas, el mito artúrico, la leyenda de Robin Hood, el teatro jacobino, las obras de Shakespeare, William Blake (1757-1827), M. R. James (1862-1936), Winsor McCay (1867-1934), H. P. Lovecraft (1890-1937), Dorothy Parker (18931967), William Faulkner (1897-1962), Mervyn Peake (1911-1968), William Burroughs (1914-1997), Ray Bradbury (1920-2012), Truman Capote (19241984), J. G. Ballard (1930-2009), Derek Raymond (1931-1994), Harlan Ellison (1934), John Sladek (1937-2000), Michael Moorcock (1939), Angela Carter (1940-1992), Iain Sinclair (1943), Stephen King (1947) y por supuesto los autores de los cómics de su juventud de entre los que destacan Jack Kirby (1917-1994), Stan Lee (1922) y Robert Crumb (1943). Vemos así una gran variedad de referentes que abarcan múltiples disciplinas, pues para Moore no solo son importantes la fantasía y la ficción, sino también la ciencia, la física y las matemáticas como indispensables motores para el desarrollo de sus trabajos. Pero sin duda, será la magia la que desempeñará un papel destacado a partir de su conversión el 1993. En su cuarenta cumpleaños, Alan Moore experimentó una transformación que lo encaminó a través de los senderos del ocultismo y el ceremonial mágico, de la gnosis, del esoterismo, de la alquimia, de los estudios cabalísticos, del hermetismo, de la psicogeografía, de la filosofía oculta y de lo extradimensional ${ }^{10}$; además lo llevó a adoptar como dios a Glycon ${ }^{11}$. De la mano de las historias y hechos de personajes relacionados con lo arcano y la mística como John Dee (1527-1608/1609), Emanuel Swedenborg (1688-1772), Eliphas Lévi (1810-1875), Austin John Kendrick Bangs (1862-1922), Osman Spare (1888-1956) y en especial Aleister Crowley (18751947), Moore pasará a entender el arte como una extensión de la propia magia, pues ambas comparten un mismo lenguaje (Moore, 2014 [2002]; Liddo, 2009, 29; Berlatsky, 2011, X-XI; Hanegraaff, 2016, 236-239) ${ }^{12}$. Moore afirma al respecto que:

${ }^{10}$ Estas disciplinas se ocupan de los misterios de la sabiduría suprema o de aquello oculto a los sentidos, es decir, conocimientos que no se basan en la experimentación científica.

11 "While Watchmen engaged with Einsteinian and quantum physics, and Big Numbers explored the significance of fractal mathematics and chaos theory, Moore's turn to magic, the kabbalah, Aleister Crowley, and his own notion of neoplatonic 'Idea Space' would seem to be a turn toward the irrational. In fact, however, the 'magic' Moore most avidly preaches is the power of the human imagination, particularly through art and writing". Berlatsky, 2011, XI.

${ }^{12}$ Para incrementar su inmersión en el subconsciente y en el espiritismo, Moore consume sustancias psicoactivas y alucinógenas como hongos psilocibios. Hanegraaff, 2016, 237-238. 
El acto definitivo de magia consiste en crear de la nada: como cuando sacas un conejo del sombrero (el acto alquímico) [...]. Puedes convertir una idea en una película, un libro, una obra musical, algo que los demás puedan experimentar (magia y arte). Eso es en sí algo sorprendente (Moore, 2014 [2002], 27).

\section{DE PROMETEO A PROMETHEA}

Como resultado de esta inmersión al cosmos de lo oculto y espiritual es el nacimiento de Promethea, receptáculo para presentar la nueva etapa sensorial que había emprendido Moore. Así, el universo creado para este cómic ya da testimonio de la creciente influencia de lo mágico -aunque mantiene también sus referentes anteriores- al ubicarlo entre dos reinos separados y antagónicos que, sin embargo, necesitan de sí para poder coexistir: la realidad y la Inmateria, el plano de lo imaginario y de la conciencia. Esta división de la existencia basada en la que realiza Platón (c. 427-347 a.C.) en su República (c. 380 a.C.) con el mundo sensible y el intangible, le sirve a Moore para establecer una escisión entre el lugar donde reside la humanidad y aquel en donde viven las ideas y todo lo imposible es posible. En esta dimensión vive un ente femenino conocido como Promethea y que originariamente fue una pequeña niña que quedó huérfana al asesinar a su padre un tumulto de cristianos en la Alejandría del 411 d.C. por ser practicante de magia y de los ritos paganos. Sin embargo, el dios Thot-Hermes se le aparece y le explica que debido a la aparición de un nuevo dios sus sacerdotes están muriendo y su influencia desaparece, por lo que solamente podrán protegerla y se va con ellos a su mundo, a la Inmateria, para convertirse en una historia. Promethea pregunta si eso significa que seguirá viviendo o no, a lo que la divinidad contesta que si una historia es especial a veces puede apoderarse de la gente (\#1.21:1-6) ${ }^{13}$ (Means-Shannon, 2010, 98; Sánchez Pérez, 2015, 278-279).

No será hasta más adelante cuando entendamos este punto, pues como descubriremos, Promethea puede, mediante el arte o la poesía, encarnarse en diversos receptáculos humanos, asumir una carnalidad y caminar entre los mortales a modo de diosa o semidiosa, dado que al ser una historia/idea no puede manifestarse físicamente por ella misma ${ }^{14}$. De hecho, Moore crea un ensayo ficticio (The

${ }^{13}$ El \#1 hace referencia al número de la serie, el 21 a la página y el 1-6 a las viñetas. Utilizaremos este sistema de citación a lo largo del artículo; sirva esta aclaración de ejemplo para los que vendrán a continuación. La edición consultada corresponde a la de ECC Ediciones (2016) versión en castellano y recogida en tres tomos.

14 "Promethea reappears by coming into being time and time again in different iterations through specific human women. As culture changes, as time moves, and the human 
Promethea Puzzle: An Adventure in Folklore) a modo de preludio retratando como han ido emergiendo y configurándose las distintas versiones de Prometheas desde la Charlton Sennet de 1780 a la de Steven Shelley, pasando por la de Margaret Case y Grace Brannagh; su intención es hacer creer al lector que efectivamente estas narraciones fueron reales. ${ }^{15}$ Como se nos revelará más adelante, cada autor/a de los relatos es en realidad una manifestación de Promethea, ya fuera a través de ellos mismos o por medio de algún familiar o allegado y que actualmente viven en la Inmateria, puesto que, aunque sus cuerpos desaparecieron, no así la historia de sus vidas como semidiosas (Means-Shannon, 2010, 98-99; Howell, 2015, 385; Hanegraaff, 2016, 240-241).

Y es de esta forma como empieza el cómic, con la búsqueda de información relativa a la historia de Promethea por parte de una estudiante neoyorkina para un trabajo, Sophie Banks, que en 1999 se convertirá en su último y más poderoso recipiente y con el que finalmente provocará el apocalipsis, pues si algo caracteriza la obra de Moore es su interés por retratar el fin del mundo. No obstante, hay que entender este término no como Apocalipsis, es decir, por su adscripción religiosa, sino como apocalipsis, sin connotaciones en relación al cristianismo y como simple final de la creación. Proveniente del griego apokalypsis, esta palabra se traduce como revelación es recogida por Moore como una disrupción en la manera de pensar de la gente más que como una destrucción física de la creación. Así, Promethea se convierte en una encarnación del concepto del apocalipsis como cambio de creencias a través de trasformar las estructuras ideológicas por medio de la fuerza y el poder de la imaginación (Kraemer y Winslade, 2010, 275-276; Cortsen, 2014, 402, 407).

Pero para poder lograrlo, Promethea deberá enfrentarse al Templo, una organización que intentará poner freno a los intentos de la superheroína y a los diablos que le envían ${ }^{16}$. Para ella, su cometido no es otro que traer la luz al mundo, recordarles las posibilidades que tiene la mente para crear magia me-

imagination shifts, so does the embodiment of Promethea. Promethea is always Promethea, but specifically reconstructed [...]. The character is always already an iteration of culturally-specific imagination, and the version of the Promethea story is born out of the needs of that particular cultural moment". Howell, 2015, 388.

${ }^{15}$ Estos personajes están basados en autores de superhéroes como Margaret Brundage, William Moulton Marston y Grace Gebbie Drayton. Klock, 2003, 112; Liddo, 2009, 87.

16 "[...] Moore is making the excellent point that contemporary Evangelicals and Christian Fundamentalists are among the most serious believers in the reality of the occult today. They really believe in demons and occult powers, arguably more so than many occultist practitioners, who tend to have a more complex, ironic, or distanced attitude towards questions of reality/unreality or existence/non-existence". Hanegraaff, 2016, 243. 
diante la imaginación. De hecho, Moore concibe a Promethea como la feminización del titán Prometeo que en los mitos clásicos fue quien trajo el fuego y el conocimiento a la humanidad (García Gual, 2009; Means-Shannon, 2010, 99). ${ }^{17}$ Una imagen del mismo Prometeo encadenado a la roca aparece en el cómic como advertencia para Promethea si no va con cuidado, pues muchos son los que quieren evitar el apocalipsis (\#7.20:1-2). Y, sin embargo, Moore no quiso rescatar la figura del titán, sino que prefirió trasladar y adaptar su mito a una figura nueva, dado que como expone en una entrevista con Tasha Robinson:

[...] I thought, well, I want a comic with a strong female character. I'd also like to have comic where I can release some of the steam of my magical researches. [...] Promethea grew out of research that I was doing anyway, something that I was already interested in, and which I suddenly realized that I could probably apply effectively to comics (Berlatsky, 2011, 107).

Aunque en algunos de los trabajos de Moore puede leerse cierta fantasía de poder masculino que bebe de la sociedad patriarcal que ve a la mujer como un objeto erótico, tal y como se recoge en la representación de forzamientos sexuales en The League of Extraordinary Gentlemen o en la disposición de Sally Jupiter por perdonar al Comediante por violarla en Watchmen, el guionista británico también ha intentado aportar un positivismo a la defensa de las sexualidades alternativas y queer, siendo Promethea uno de los mayores ejemplos (Liddo, 2009, 110; Kraemer y Winslade, 2010, 274; Berlatsky, 2011, XIII; Hanegraaff, 2016, 235). En esta, por ejemplo, encontramos una revisión de la figura de Wonder Woman mediante una de las encarnaciones de Promethea, William 'Bill' Woolcott, un ilustrador de cómics homosexual que al convertirse en la semidiosa mantendrá un noviazgo con un agente del FBI, Dennis Drucker. La relación termina violentamente con el asesinato de Bill a manos de su amante cuando este descubre que en realidad Promethea era un hombre (\#7.17:1), aunque los estragos en Dennis son tales que queda recluido en un psiquiátrico atado y con la mirada perdida (\#7.18:1-3). No obstante, tras el apocalipsis, Bill/Promethea y Dennis reprenden su idilio en la Inmateria (\#31.16:4).

Por otro lado, podemos hallar un romance entre otra Promethea, Grace y Stacia Vanderveer, íntima amiga de Sophie y que al inicio del cómic manifiesta en diversas ocasiones su aversión al lesbianismo. Sin embargo, a causa de la marcha de Sophie a la Inmateria en busca de Bárbara Shelly -la Promethea

17 A lo largo del texto hay distintas referencias a Mary Wollstonecraft Shelley y su Frankenstein, or, the Modern Prometheus (1818) y a Hélène Cixous y su Le livre de Prométhea (1983). Liddo, 2009, 87. 
anterior a Sophie-, Grace se materializará en Stacia y juntas pasaran a convertirse en la nueva protectora de Nueva York a la par que en amantes. Pero a la vuelta de Sophie, esta reclama su lugar como la actual Promethea, hecho que desencadena una batalla entre Sophie y Grace/Stacia paralelándolo Moore con las Cruzadas, pues hubo ya en el pasado un enfrentamiento entre dos personificaciones de Promethea, una cristiana y otra musulmana. De este modo, durante el combate entre Sophie y Grace/Stacia se van intercalando imágenes del encuentro violento entre las dos Prometheas del pasado (\#24.15:1-3; \#24.16:1-3; \#24.18:1-7; \#24.19:1-7) hasta el choque final. En este las dos heroínas aparecen a punto de desfallecer gritando y llorando con el símbolo de la luna y el sol rotos, y superpuestas las imágenes de las encarnaciones cristiana y musulmana y la de la pequeña y primigenia Promethea también aullando de dolor mientras que alrededor el mundo estalla (\#24.20-21:1). El mensaje aquí es claro, pues Moore vincula el cristianismo y el islam como dos aspectos de la misma idea, el monoteísmo, y de lo trágico y destructivo de las guerras y batallas que en sus nombres se han hecho, si bien no deja de ser revelador que, aunque no hay vencedora, Sophie está en el lado del sol y de Cristo mientras que Grace/Stacia, que intentan usurpar su cargo, van con la luna y con el Profeta (Kidder, 2010, 159-164).

\section{DE SEFIROT EN SEFIROT ${ }^{18}$}

Pero sin duda alguna, el peso principal de Promethea, al menos para nuestro tema de estudio, es el viaje astral que realiza Sophie a través del Árbol de la Vida junto con Barbara Shelley, otro alter ego de Promethea ${ }^{19}$. Esta, tras morir por unas heridas sufridas protegiendo a la propia Sophie, decide embarcarse en la búsqueda de su marido, que había fallecido años atrás. Cuando Steven Shelley desaparece, Barbara pierde el esplendor de los días pasados como Promethea, al ser ella únicamente el recipiente donde se manifestaba a través de los dibujos de su marido. Desaparecido este, Barbara solo es capaz de recordar a la semidiosa vagamente y su transformación no es adecuada. Así, una vez traspasado el umbral de la vida, Barbara decide sumergirse en la Inmateria para poder encontrar a su marido. Sophie que se niega a perder a su querida amiga, decide seguirla, no sin antes haber asistido a una serie de lecciones que

18 A partir de este punto narraremos los acontecimientos que van sucediéndose a lo largo de la historia intercalando las interpretaciones que de ello hemos extraído tras un profundo análisis.

19 "The Promethea of 1999 is going to be Sophie, whose name clearly hints at the long journey into knowledge she embarks on as the story unfolds". Liddo, 2009, 89. 
la fueron guiando por los caminos de lo mágico y la imaginación para de esta forma poder adentrarse en la Inmateria. Por medio de las historias vividas de las antiguas Prometheas descubrió los signos de la magia: la Copa de la compasión (\#5), la Espada de la razón (\#6) y la Moneda del espíritu (\#7), mientras que con el mago Jack Fausto se inició en los misterios de la Varita (\#10) (Liddo, 2009, 148; Means-Shannon, 2010, 101; Hanegraaff, 2016, 244-245). En este caso y a diferencia de los anteriores, Sophie tuvo que pagar un precio como Promethea: acostarse con el viejo, calvo y con sobrepeso Fausto. No obstante, como apunta Howell:

When they come-together, perfectly-it is tantric, the most transcendent of petite mort, it is consensually pleasing for the characters, it is beautiful, yet it is monstrous for us to behold, horrible to see. We readers are forced, in our discomfort, to ask why this moment of magic and pleasure signifies as so radical, as so defiantly and disturbingly taboo. Why is loving the Other, crossing the boundary of individuated selfhood or stable subjectivity with the Other, taking the Other into oneself, so frightening? [...] Sophie/Promethea joins with the sorcerer, taking him in body and soul, and in that unity, our protagonist becomes even more powerful as her knowledge grows (Howell, 2015, 391).

Su viaje final, antes de adentrarse en la Inmateria lo hará a través de las serpientes de su báculo, Mack (macrocosmo) y Mike (microcosmo) (\#12). Al haber sido recogida de pequeña por el dios Thot-Hermes, Promethea manifiesta algunos de sus atributos. Del dios griego podemos destacar el caduceo y el casco en forma de alas en alusión a las sandalias voladoras que llevaba el hijo de Zeus. En relación a Thot encontramos el anj y el escarabajo en la lorica, un brazalete de serpiente, un tatuaje de un escarabajo alado y otro de la efigie de Thot en la pierna derecha; el dorado y los símbolos solares podrían aludir a Ra. Además, Sophie/Promethea sirve como guía con la humanidad, del mismo modo que Hermes lo era con las almas que trasladaba al inframundo (Means-Shannon, 2010, 99-101; Sánchez Pérez, 2015, 279-282; Hanegraaff, 2016, 245-246) ${ }^{20}$.

De esta manera, a través de Mack y Mike, conoce la historia del universo por medio de las 22 cartas del Tarot, la cual empieza desde un nivel físico con el Big Bang y el vacío quántico a la emergencia de la Tierra y la vida. Después pasaremos a la historia cultural con las sociedades primitivas chamánicas y continuaremos por la erección y caída del Imperio Romano, la noche eterna

${ }^{20}$ La vinculación iconográfica de las otras Prometheas con referentes divinos es clara también en el caso de Margaret Case, cuya figura, bien que sexualizada, mantiene algunos rasgos que la podrían vincular con Atenea. 
de la Edad Media, la edad de la razón, la revolución industrial y los horrores de las Guerras Mundiales que originan la fase psicodélica que terminará con la evolución espiritual y el fin del mundo: la revelación (Kraemer y Winslade, 2010, 279-282; Berlatsky, 2011, 112; Hanegraaff, 2016, 246) ${ }^{21}$.

Con todo ese conocimiento a su disposición, Sophie por fin es capaz de penetrar en la Inmateria para descubrir que esta no es sino una manifestación de la Cábala judía, el Árbol de la Vida (Howell, 2015, 389-390)22. El universo se encuentra dividido en diez esferas conocidas como sefirot y se configura como un reflejo del alma humana a través de un mapa conceptual a nivel cósmico, donde lo visual y lo lingüístico se combinan para facilitar la comprensión de la filosofía oculta y abstracta. Cada sefirot, adscrita a un astro celeste y un color, representa un modo distinto de conciencia y son emanadas directamente de la divinidad. Las distintas esferas se imbuyen, como veremos, de un estilo distinto -desde la estética de Vincent Van Gogh (1853-1890) a la de Andy Warhol (1928-1987) pasando por la de Alphonse Mucha (1860-1926) - que, a medida que Sophie y Barbara van subiendo por el árbol, irán derivando a la abstracción, simbolizando así el abandono del mundo físico por la inefabilidad de la realidad y la existencia. Por otra parte, las esferas se intercomunican entre sí mediante 22 caminos que referencia a las 22 letras del alfabeto hebreo y que representan un estado, sefirá, que aproxima a la comprensión de Dios y de la creación del mundo. La unión de las sefirot y los 22 senderos dan lugar a las 32 rutas hacia el conocimiento y la percepción trascendental (Liddo, 2009, 86, 92; Kraemer y Winslade, 2010, 282; Means-Shannon, 2010, 101; Hanegraaff, 2016, 246).

Como se ve en Promethea ${ }^{23}$, la estructura de la Cábala se divide en dos cuerpos, el inferior formado por Maljut (Reino), Yesod (Fundamento), Hod (Esplendor), Netsaj (Victoria) y Tiféret (Belleza) y más ligado al mundo ma-

${ }^{21}$ Cada carta representa un estadio de la humanidad: el Mago el Big Bang, el Colgado los tiempos oscuros, el Arte (o la Templanza) el Renacimiento, la Torre la industrialización, la Luna el periodo nuclear y el Sol la década de los 60. Kraemer y Winslade, 2010, 280.

${ }^{22}$ Como apuntan Kraemer y Winslade, la popularidad de Promethea fue tal que "the comic has become known in the occult and Pagan communities as an accessible introduction to hermetic kabbalah. [...] An October 2007 newsletter produced by a body of the occult order Ordo Templi Orientis in Kentucky reviewed the books as 'an ideal teaching tool for new magicians,' advertising Promethea next to articles on Pagan Pride Day and contemporary Pagans in the military". Kraemer y Winslade, 2010, 288. Además, a lo largo de todas las páginas, Moore y Williams III van añadiendo distintas representaciones esquemáticas de la Cábala.

${ }^{23}$ Toda referencia y comentario cabalístico dado a partir de ahora, será siempre bajo la óptica e interpretación de la obra de Moore, por lo que no podría coincidir con las diferentes lecturas que del Árbol de la Vida se han dado. 
terial. Este último une las dos partes del entramado, pues el tronco superior es el más cercano a la divinidad y se conforma por Guevurá (Fuerza y Jucio), Jesed (Piedad), Biná (Comprensión), Jojmá (Sabiduría) y Kéter (Corona) ${ }^{24}$. De esta, raíz de donde emana el rayo divino, deriva a los dos principios complementarios, Jojmá y Biná y que conforman la tríada intelectual, para ir bajando por las sefirá hasta Maljut, la Tierra, el más alejado de todas las sefirot y donde reside la humanidad ${ }^{25}$.

Será a partir de aquí que Sophie emprenda su viaje, por la ruta 32, encontrándose con una representación del universo con la figura de una mujer y un reptil enroscado danzando y enmarcados a modo de cardinales, los cuatro elementos, tierra, agua, fuego y aire (\#13.18-19). Pero estos tienen como particularidad el simbolizarse como un toro, un hombre, un león y un águila respectivamente, del modo en que se han representado los cuatro evangelistas como tetramorfos. Esta elección de figuras cristianas como configuradoras del cosmos y que ya han aparecido en anteriores ocasiones (\#7.14:1; \#13.14; \#13.15) le sirven a Moore para encuadrar a la figura de la joven y la serpiente y que son definidas, ella como la imaginación y la sierpe como las cosas terrenas que crecen, el ADN (Liddo, 2009, 151). Su danza cósmica es la que da origen al universo. La mujer que a priori podría confundirse con la de Eva, pues ella es la primera madre y cuya imagen va ligada casi siempre con la del ofidio, tiene también mucho de María, al tener una luna en la cabeza y encontrarse la cabeza del reptil entre sus pies tal y como se ve en las reproducciones visuales de la Inmaculada. Así, con este juego de dualidades entre evangelistas/elementos, (Eva/Ave María)/serpiente y materia/imaginación, Moore desacraliza estas imágenes del cristianismo para esgrimir solamente la carga iconográfica. Sin embargo, al tratarse en Promethea a los dioses y diosas de las religiones del mundo como entes vivos en la Inmateria, sigue habiendo una carga mística en cada una de estas representaciones.

Su siguiente estadio será Yesod, la Luna, donde llega por medio de Caronte que la cruza por el Estigia en una barca con elementos que aluden al Antiguo Egipto como el anj, jeroglífico de la "vida" (\#13.24:1). Este trascurso lo en-

${ }^{24}$ Los nombres los hemos transcrito tal y como aparecen en la edición consultada.

25 "Rather than viewing it hierarchically as a structure with a top and a bottom, I see it as a map or circuit-diagram that connects two remote points (Ultimate God and the world of Matter) by the shortest possible route. The energy can flow either way, and the structure itself has no preference. Generally, we tend to think of the moon as being above the earth and the sun being above that (or, in Qabalah, of Yesod being above Malkuth, with Tiphareth above them both), but, in actuality, there is no 'up' or 'down' in space, nor, I believe, in the structure of the Otz Chiim [the Tree of Life]" Cfr. Liddo, 2009, 95. 
tiende Moore como una muerte espiritual -habrá otra más adelante-, pues el reino del crepúsculo gobierna los sueños y el inconsciente y es precisamente, como le dice el barquero a Sophie, en esos lugares donde encontramos a los difuntos (\#14.2:3-4). En esta misma esfera bañada por el azul oscuro de la noche lunar descubrirán al pastor Endimión durmiendo -algo excitado- y soñando con la diosa Selene, dado que solo a través de otro estado de consciencia se puede llegar a establecer contacto con la divinidad (\#14.18:1-4). En Yesod encontrará además a una Barbara afligida que no puede hallar a su esposo y juntas emprenderán la subida por el Árbol hasta dar con él (Hanegraaff, 2016, 246).

A través del sendero 30, llegan a Hod, el reino del lenguaje, la comunicación, el pensamiento, la magia y las ideas. Por ello, no es extraño encontrar aquí a las deidades ligadas a estos campos como Hermes, Mercurio, Thot, Cinocéfalo, Wotan y Hanuman (\#15.14:1; \#15.15:1). El dios griego decide acompañarlas por su tierra ocre y anaranjada y les dice que todo cuanto existe lo hace gracias al lenguaje, incluso los mismos dioses. De este modo, ellos pueden estar presentes en el propio cómic, pasando a incluirse el lector, a su vez, en una narración que se desenvuelve como parte del desarrollo continuo de la creación (Kraemer y Winslade, 2010,284). Por otro lado, dado que esta sefirot se relaciona con el planeta Mercurio, la misma esfera y las divinidades están hechas con este elemento químico. Además, será en Hod donde, al discutir sobre las nociones de la eternidad, Barbara y Sophie entraran dentro de un loop espaciotemporal hasta ser conscientes de que se encuentran en una banda de Möbius, el símbolo matemático del infinito (\#15.8; \#15.9). También será aquí donde se encuentren con la primera manifestación de Aleister Crowley, el cual aparecerá bajo distintas formas en diversas ocasiones (Liddo, 2009, 93; Kraemer y Winslade, 2010, 282-284; Hanegraaff, 2016, 246).

Por la ruta 27 llegan a Netsaj, la sefirot venusiana. Basada en una estética que recuerda a las obras de Mucha, la emoción y la pasión, simbolizada por un océano esmeralda, es el atributo imperante en este territorio. A causa de naufragar en este mar de sentimientos y de lágrimas y de rendirse a ellos, Barbara y Sophie dan con la fuente misma del amor, el principio sobre el que se basa todo el universo, representado con la Venus del Nacimiento de Venus (1484-1486) de Sandro Botticelli (1445-1510) (\#16.16:1; \#16.17:1) (Kraemer y Winslade, 2010, 282; Hanegraaff, 2016, 246-247).

Durante su recorrido por el sendero 24 son ejecutadas por la Muerte, si bien este deceso se ve como uno material, pues están a punto de llegar a Tiféret, el Sol, la esfera del yo más elevado. Este es el punto más alto de la humanidad (la cruz) y el más alejado de Dios (el círculo) donde conectan los dos. La propia Sophie le dice a Barbara que la deidad absoluta se encuentra en Kéter, mientras que el dios de Tiféret es el que ha nacido de la existencia, como hombre, como 
su propio hijo. Pero antes de comprobar cuanta verdad esconden las palabras de Sophie, las dos Prometheas encontraran entre el dorado de esta sefirot al ángel de la guarda de Barbara, Bubu Ramírez, y al dios del Sol, la música y la armonía, Apolo coronado con una estrella de David (\#17.16:1; \#17.17:1) ${ }^{26}$. Bubu, que las acompañará hasta Jesed, pasa a explicarles, que, como el astro solar, en este reino también se encuentran los dioses alzados, los renacidos: Balder el bello, Atis, Dionisio u Osiris (\#17.18:2-3; \#17.19:2-3).

Pero sin duda, lo que más las impacta es la figura de Cristo crucificado, los brazos de la cruz del cual simbolizan las cinco esferas más ligadas al mundo terrenal (\#17.20:1; \#17.21:6). Su cabeza descansa en Tiféret, pues como había dicho anteriormente Sophie, el dios humano reside en esta sefirot y, a pesar de encontrarse clavado en el madero marchitándose, es por medio de él como recibimos el conocimiento y la luz; el punto más álgido de la humanidad sigue con ella (Hanegraaff, 2016, 247). Esta, sin embargo, no será la única alusión al poder redentor de Cristo, pues en páginas anteriores Sophie/Promethea tuvo que salvar a la ciudad de Nueva York del estagel, un material plástico y tecnificado que por el efecto del año 2000 se transformó en un monstruo. Ayudándose de su caduceo alado, Sophie/Promethea consiguió establecer contacto con la masa gelatinosa y frenar el ataque clavando su instrumento en el suelo a modo de cruz. En el cómic, el báculo aparece con las alas extendidas como los brazos del madero y con los reptiles enroscados mientras a los pies una multitud de gente lo contempla, lo señala, aplaude y da gracias (\#11.20:2). Esta imagen redentora tiene mucho que ver con la del propio Hijo de Dios en la cruz, el cual decidió sacrificarse para obtener el perdón universal y que, a su vez, también podría conectarse con el pasaje veterotestamentario de la serpiente de bronce, admirada por los israelitas que vieron en ella su salvación como así lo hacen los neoyorkinos con el caduceo. Asimismo, es revelador el paralelismo que establece Moore entre Cristo, Prometeo, Loki y la propia Promethea, pues como dirá en el último número (\#32.6), los portadores del fuego o de la luz terminan atados o crucificados como castigo, condena que podría sucederle a la semidiosa de fracasar en su intento de provocar el apocalipsis (Howell, 2015, 390).

Por la ruta 22 llegan a Guevurá, Marte, el reino de la guerra y la justicia con los avatares rojos y negro de Ares, Horus u Odín donde son atacadas por el demonio Asmodeus (\#18.6:1; \#18.7:1), mientras que por el sendero 19 son conducidas hasta Jesed, Júpiter. Esta sefirot de azul celeste, llena de nubes y sin formas claras, cuya estética resuena en las pinturas de Van Gogh, corres-

${ }^{26}$ De acuerdo con Moore, este símbolo nace de la unión de Jojmá, el triangulo (hombre), con Biná, un triangulo al revés (mujer): el hijo (\#22.12:2). 
ponde a la esfera del padre. Pero, además, es en este lugar donde la energía de Dios se derrama y se materializa, donde empieza a existir, en el cielo protector. Por ello, los dioses de este plano serán aquellos padres supremos y celestiales como Zeus, Thor, Indra, divinidades del rayo (\#19.8:1-2; \#19.9:1-2), Poseidón, progenitor de caballos (\#19.14:1-2; \#19.15:1-2) y de nuevo Cristo en su acepción de Buen Pastor (\#19.10:1-2; \#19.11:1-2). En este mismo lugar, Sophie y Promethea se reunirán con sus padres una vez más (Liddo, 2009, 92; Hanegraaff, 2016, 247).

Tras abandonar Jesed y antes de llegar la triada divina por la falta de una ruta, Sophie y Barbara deben saltar al abismo de Daath, el Conocimiento, una falsa sefirot ultravioleta a la que le dan el número pi (3'14) por encontrarse entre la esfera tercera y cuarta. Según se cuenta por boca de Austin Spare, Daath simboliza la escisión entre la tríada celestial y las esferas inferiores, dando lugar a la necesidad de adquirir el conocimiento a través de su ausencia (\#20.16:1-5; \#20.17:1-5). Desde aquí llegaran por fin a Biná, Saturno, el reino femenino donde Sophie/Promethea y Barbara/Promethea experimentan una trasformación tanto física como espiritualmente, perdiendo la primera casi la totalidad de los atributos que la caracterizaban y obteniendo en su frente el símbolo del Ojo de la providencia. En esta sefirot negra, ocre, escarlata y azul, serán guiados por John Dee hasta la figura del Eterno Femenino, formada por las energías femeninas de la prostituta de Babilonia, Babalon y de la Virgen María en su representación como Inmaculada, con la serpiente a los pies y la luna y las doce estrellas sobre la cabeza, imagen que recuerda a la Eva/María que aparece como figuración del universo (\#21.14-22). Babalon por su parte aparece a lomos de una bestia de siete cabezas y con la copa de la comprensión en la mano, ligándose así estos personajes a los que aparecen en el Apocalipsis de san Juan y que, a su vez, indirectamente refuerzan el cometido de Promethea como provocadora de la revelación (Ap. 12, 1-4) (Hanegraaff, 2016, 247-248).

Vemos de este modo la importancia que para Moore desempeña el concepto de dualidad que, como hemos visto concibe a lo largo de toda la historia como con Promethea y sus recipientes, la materia y la imaginación, o la misma feminidad representada por Babalon y María, pero también con Isis, Hécate o Selene (\#21.20:2); de hecho hay también una doble imagen de la Virgen ocultando a Jesús de Herodes y a su lado, Isis con Horus haciendo lo propio con Set (\#21.20:4). Este interés por el desdoble de una misma naturaleza continúa en Jojmá, las Estrellas, la esfera grisácea del aspecto masculino más elevado, reino de lo sagrado y profano donde las energías femeninas y varoniles copulan hasta provocar el Big Bang a través del acto primario y sexual entre Pan y Sémele (\#22.14-15) (Means-Shannon, 2010, 93-104; Hanegraaff, 2016, 247-248). 
Finalmente, por la ruta 11, la del Loco, llegan a Kéter, la chispa blanca del ser, la morada de Dios, el Todo. En esta última sefirot, Barbara encuentra a Steven y los dos se transforman en una especie de Adán y Eva míticos, reunidos de nuevo en el Principio (Hanegraaff, 2016, 248). Al llegar a este punto del viaje, dos opciones se presentan ante los tres personajes y cuyo eco encontramos en la alegoría de la caverna de Platón: permanecer en Kéter o volver a Maljut, es decir, quedarse en el mundo de las ideas o volver a la caverna a liberar a nuestros compañeros encadenados. Como Steven apunta, al subir por el Árbol somos como serpientes que vamos escalando y ascendiendo, somos la voluntad de vivir. Sin embargo, al descender, al regresar a la confusión y sufrimiento del mundo, somos palomas, pues ella representa la voluntad de sacrificarse, de volver a la materia y de llevar un poco de luz a la humanidad (\#23.14-15). De hecho, durante el orgasmo cósmico entre Pan y Sémele en Jojmá aparece un ave columbina entrando en una copa y detrás una estrella de David, símbolo del linaje de Jesús en la tierra (\#22.14-15) (Patton, 2012, 128$131)^{27}$. Así, no deja de ser revelador que justamente el regreso a Maljut sea imaginado mediante la figura de una paloma, misma imagen que ha utilizado el cristianismo para representar el Espíritu Santo y cómo a través de él se encarnó Cristo en el recipiente que era María. De este modo, Sophie, Barbara y Steven, al igual que el Hijo de Dios, deciden lanzarse por el vacío hasta la Tierra en forma de colúmbidos y reencarnarse ambos amantes en dos hermanos gemelos (\#23.24:1-4).

\section{A MODO DE CONCLUSIÓN}

Como se ha comprobado a lo largo del texto, Promethea es sin duda uno de los mejores ejemplos que disponemos a la hora de analizar la impronta de la divinidad desacralizada en la actualidad, presentando a estos personajes celestiales como productos del imaginario colectivo, que, sin embargo, están $\operatorname{vivos}^{28}$. De esta forma, hemos asistido a una especie de alquimia espiritual, de la que hablaba Jung en Psychologie und Alchimie (1944), en la que lo incons-

27 También será en esta esfera, antes de subir a Kéter por unas escaleras, que se encuentren fluyendo desde la inmensidad blanca de la siguiente sefirot una bandada de estos pájaros y la figura de una serpiente enroscada a un árbol en la parte inferior derecha, preludio del siguiente capítulo (\#22.24).

${ }^{28}$ Aunque a lo largo del cómic hay otras manifestaciones iconográficas de dioses y diosas, por límites de espacio, hemos preferido centrarnos en aquellos que aparecen a lo largo del viaje cabalístico por ser los ejemplos más numerosos. 
ciente se tornaba consciente y la divinidad adquiría consistencia y realidad. Su presencia, como ha quedado patente, se detecta en casi cada página, a veces como mero elemento decorativo y otras como soporte esencial para el entendimiento de la concepción de la mente humana. Para Alan Moore, no hay diferencia entre Zeus o el Buen Pastor, Thot o Hermes, o Babalón y María, puesto que no es dios en sí lo que interesa, sino la representación de los valores que encarna, ya sea la bondad, la desesperación o el conocimiento, pues en una suerte de uróboros, la humanidad había concebido esas entidades para poder ser dados a luz por ellos, empezar a existir y poder imaginarlos. Y aunque el mismo Moore niega que Promethea tenga intenciones religiosas, admite que sí es "a magical rant disguised as a superheroine comic", entendiendo magia como "simply a new way of seeing the ordinary universe that surrounds us, and ourselves as creatures in that universe" (Kraemer y Winslade, 2010, 288).

La intención del texto ha sido la de describir la travesía de Sophie y Barbara casi paso a paso para poder detenernos y analizar la gran cantidad de alusiones a referencias mágicas, divinas o religiosas. Consideramos que este método resultaría más provechoso a la hora de comprar esas imágenes o escenas con sus prototipos, ofreciendo una perspectiva global del imaginario de sus artífices. Tal y como Moore y Williams detallan, los caminos para acceder a Kéter son varios, encontrando en cada uno de ellos varias deidades distintas a modo de panteón ecléctico que perpetúa la continuación y difusión de los mitos, las leyendas y las historias de estos seres divinos que poblaron y pueblan templos, rezos y hornacinas. Sin embargo y como hemos visto, de un modo u otro, santos y dioses también han bajado de los altares y se han trasladado a las estanterías.

\section{BIBLIOGRAFÍA}

BERLATSKY, E. L. (2011): Alan Moore: Conversations, Jackson, University Press of Mississippi.

CORTSEN, R. P. (2014): "Full page insight: the apocalyptic moment in comics written by Alan Moore", Journal of Graphic Novels and Comics, 5:4, 397-410 p.

GARCÍA GUAL, C. (2009): Prometeo: Mito y Literatura, Madrid, Fondo de Cultura Económica de España, 239 p.

HANEGRAAFF, W. J. (2016): "Alan Moore's Promethea: Countercultural Gnosis and the End of the World", Gnosis: Journal of Gnostic Studies, 1, 234-258 p.

HOWELL, T. L. (2015): "The Monstrous Alchemy of Alan Moore: Promethea as Literacy Narrative", Studies in the Novel, 47:3, 381-398 p.

KIDDER, O. U. (2010): Telling Stories About Storytelling: The Metacomics of Alan Moore, Neil Gaiman, and Warren Ellis, Edmonton, Library and Archives Canada, $200 \mathrm{p}$. 
KLOCK, G. (2003): How to read Superhero Comics and Why. Nueva York; Londres, Continuum, $216 \mathrm{p}$.

KRAEMER, C. H.; WINSLADE, J. L. (2010): “'The Magic Circus of the Mind”: Alan Moore's Promethea and the Transformation of Consciousness through Comics" en: Lewis, A. D.; Kraemer, C. H. (eds.), Graven Images: Religion in Comic Books and Graphic Novels, New York, Continuum, 274-291 p.

KOVACS, G.; MARSHALL, C. W. (2011): Classics and Comics, Oxford, Nueva York, Oxford University Press, 265 p.

KOVACS, G.; MARSHALL, C. W. (2016): Son of Classics and Comics, Oxford, Nueva York, Oxford University Press, 288 p.

LEWIS, A. D. (2010): "Superman Graveside: Superhero Salvation beyond Jesus" en: Lewis, A. D.; Kraemer, C. H. (ed.), Graven Images: Religion in Comic Books and Graphic Novels, New York, Continuum, Edición de Kindle, sp. / 366 p.

LIDDO, A. D. (2009): Alan Moore: Comics as Performance, Fiction as Scalpel, Jackson, University Press of Mississippi, $201 \mathrm{p}$.

MATHEWS, T. F. (1993): The Clash of Gods: a reinterpretation of Early Christian, Princeton (NJ), Princeton University Press, 223 p.

MEANS-SHANNON, H. (2010): "Seeing double: the transforming personalities of Alan Moore's Promethea and the Ulster Cycle's Cuchulain", Journal of Graphic Novels and Comics, 1:2, 93-104 p.

MOIX, T. (2007). Historia social del comic, Barcelona, Bruguera, 396 p.

MOORE, A. (2014 [2002]): Ángeles Fósiles [prólogo de Servando Rocha], Madrid, La Felguera, $161 \mathrm{p}$.

ORCUTT, D. (2010): "Comics and Religion: Theoretical Connections" en Lewis, A. D.; Kraemer, C. H. (eds.), Graven Images: Religion in Comic Books and Graphic Novels, New York, Continuum, Edición de Kindle, sp. / 366 p.

PATTON, Pamela (2012): Art of Estrangement: Redefining Jews in Reconquest Spain, Pennsylvania, Pennsylvania State University Press, 220 p.

ROMERO-JÓDAR, A. (2013): "Comic Books and Graphic Novels in their Generic Context. Towards a Definition and Classification of Narrative Iconical Texts", Journal of the Spanish Association of Anglo-American Studies, 35.1, 117-135 p.

ROUGH, B. (2016): Are Videogames Art?, ProQuest, 258 p.

ROUND, J. (2010): “The Apocalypse of Adolescene': Use of the Bildungsroman and Superheroic Tropes in Mark Millar and Peter Gross' Chosen", en: Lewis, A. D.; Kraemer, C. H. (eds.), Graven Images: Religion in Comic Books and Graphic Novels, New York, Continuum, 188-202 p.

ROTH, L. (2010): “Drawing Contracts: Will Eisner's Legacy” en: Lewis, A. D.; Kraemer, C. H. (eds.), Graven Images: Religion in Comic Books and Graphic Novels, New York, Continuum, Edición de Kindle, sp. / 366 p.

SÁNCHEZ PÉREZ, C. (2015): "La recepción del Corpus hermeticum en Promethea de Alan Moore" en: Movellán, M.; Verano, R. (eds.), E BARBATVLIS PVELLISQVE. Actas del II Congreso Ganimedes de Investigadores Noveles de Filología Clásica (2013), Sevilla, HABIS Anejo I, 275-283 p. 
STRÖMBERG, F. (2010): Comic Art Propaganda: A Graphic History, Lewes, Ilex, $175 \mathrm{p}$.

TRIPP, A. (2010): "Killing the Graven God: Visual Representations of the Divine in Comics" en: Lewis, A. D.; Kraemer, C. H. (eds.), Graven Images: Religion in Comic Books and Graphic Novels, New York, Continuum, Edición de Kindle, sp. $1366 \mathrm{p}$.

UNCETA GÓMEZ, L. (2007): "Mito clásico y cultura popular: reminiscencias clásicas en el cómic estadounidense". EPOS 23, 333-344 p.

UNCETA GÓMEZ, L. (2013): "La musa vejada. Clasicismo posmoderno y nuevas vías de investigación" en: Pino Campos, L. M.; Santana Henríquez, G. (eds.),

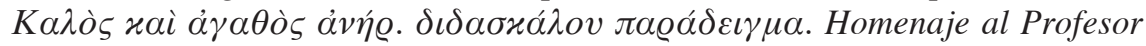
Juan Antonio López Férez, Madrid, Ediciones Clásicas, 821-827 p.

WARBURG, A. (2005): El renacimiento del paganismo: aportaciones a la historia cultural del Renacimiento europeo [traducción Felipe Pereda y Elena Sánchez], Madrid, Alianza Editorial, 624 p. 